\title{
Assessing digital records authenticity in a Botswana government accounting system: an archival diplomatics perspective
}

\author{
Olefhile Mosweu ${ }^{1}$ \\ olfmos@gmail.com ORCID: 0000-0003-4404-9458
}

Received: 21 March 2020

Accepted: 18 May 2020

\begin{abstract}
The purpose of this paper was to assess whether Botswana's Government Accounting and Budgeting System (GABS), an enterprise resource planning (ERP) system, generates digital records and maintains them as authentic over time. GABS was deployed by the Accountant General's Department (AGD) in the Ministry of Finance and Economic Development (MFED) to manage accounting and financial management processes from budgeting to expenditure. Business applications such as ERPs generate digital records whose authenticity over time may not be guaranteed because, by design, they are not recordkeeping systems. This qualitative study used concepts influenced by archival diplomatics as a theoretical lens to assess the authenticity of records generated and stored in GABS. Data was collected through systems analysis and interviews with purposively selected information and communication technology (ICT) professionals at AGD. The study found that GABS generates authentic digital records as theorised by archival diplomatics. The records are thus authentic enough to support auditing processes in the public sector of Botswana.
\end{abstract}

Keywords: Accounting, archival diplomatics, audit process, authenticity, Botswana, digital records, Government Accounting and Budgeting System

\section{Introduction}

The emergence of the concept of e-government in the 1990s led to structural and process changes in public administration, evidenced by increased deployment of different information and communication technology (ICT) platforms and applications for efficient and effective service delivery (Evans \& Yen 2005, Wamukoya \& Mutula 2005a, Sisman 2012). ICTs enabled the creation, storage, modification, distribution and preservation of digital records in a networked environment. This capability posed a series of challenges for custodians who now had to learn how to maintain such systems (Park 2001, Jansen 2014). The challenges are technical and administrative in nature, such as in cases where the technological infrastructure for the acquisition and maintenance of resultant digital records needs to ensure their authenticity in the long term (Jansen 2014).

E-government services, such as acquiring and providing products as well as obtaining information or completing business transactions, are expected to be done digitally (Fang 2002). According to Makhura (2005), in recent years, ICTs have positioned themselves as tools for the creation, access and retrieval of records. It is against this background that digital records generated from business systems need to be captured as authentic and reliable business records (South Carolina 2007). Trustworthy information systems are reliable, authentic and have integrity. Tafor (2003) and Stair and Reynolds (2006) cautioned that digital records are susceptible to easy manipulation but should still remain available, usable, understandable and authentic for as long as needed. It is therefore imperative that records generated by digital systems be authentic and that such authenticity be maintained as long as the records are used in business processes on which to base decisions.

The quest for maintaining the authenticity of records has a long history. Developed by Mabillion in the late $17^{\text {th }}$ century, diplomatics was concerned with proving the authenticity and, indirectly, the reliability of archival documents for establishing the existence of patrimonial rights of the church, religious orders and other authorities. It was also used to identify and eliminate forgeries (Duranti 1997, Duranti 2014). Traditionally, diplomatics has been defined as "written testimony or evidence of a juridical fact, produced by a natural or juridical person in the course of practical-administrative activity, and kept for action or reference by that same person or its legitimate successor(s)" (Duranti 1997). Although the definition perfectly suited the purposes of diplomatics and archival science (for some time), it was found wanting for the research

1. Olefhile Mosweu is Post-Doctoral Research Fellow, Department of Information and Knowledge Management, University of Johannesburg, South Africa 
purposes of the University of British Columbia's International Research on Permanent Authentic Records in Electronic Systems (InterPARES) when the research team tried to apply it to the digital records creation environment (Duranti 1997). Mak (2012) simply defined diplomatics as the systematic analysis of documentary evidence. It offers a method of interpretation founded on the close study of archival sources, including their material, form and the conditions of their production.

\section{The context of the study}

The study was conducted at the Department of Accountant General (AGD) within the Ministry of Finance and Economic Development (MFED), Botswana. AGD manages government expenditure against a budget drawn up each financial year by MFED after consolidating submissions from line ministries of the Government of Botswana. AGD implemented the Government Accounting and Budgeting System (GABS), an enterprise resource planning system (ERP) in 2004 for the following reasons:

- To increase the ability to undertake central control and monitoring of expenditure and receipts in the ministries and departments.

- To provide up to date and online information on the government's cash position and economic, financial and operational performance.

- To eliminate the duplication of maintaining the same information.

- To process the budget preparation faster, close accounts and process other transactions.

- To enhance the ability to demonstrate accountability to donors and to the public by having a proper audit trail of transactions in the system.

\section{Empirical studies on authenticity of digital records}

For three decades prior to 1997, archivists and records managers strived to keep up with continuous changes inherent in digital information systems containing records (Cox 1997). System designers, high-technology companies and information policymakers, among others, produced volatile solutions and digital information infrastructure that could render obsolete solutions thought to be viable only a few years before. The endeavour to produce reliable systems for the creation and maintenance of digital records resulted in several empirical studies. These included the University of Pittsburgh project, the UBC-MAS project and International Research on Permanent Authentic Records in Electronic Systems (InterPARES) (Duranti \& MacNeil 1996, Cox 1997, Bearman \& Sochats 2002).

\subsection{The University of Pittsburgh project}

The University of Pittsburgh project, which set out to develop functional requirements for record keeping in digital environments, was jointly led by Professor James Williams and Professor Richard J. Cox of the University of Pittsburgh's School of Information Sciences following a research grant of $\$ 359,560$ received from the National Historical Publications and Records Commission in 1993 (Cox 1997). According to Duff (1996) and Rogers (2015a: 32), the project focused on recorded transactions. Undertaken over three years, the project produced a set of nineteen functional requirements for digital evidence based on literary warrant (Rogers 2015a). Rogers (2015a) stated that, although the project did not address the authenticity of records explicitly, it produced requirements supported by trustworthiness and accountability. The recordkeeping functional requirements were observable and measurable to the extent that software engineers could use them to develop systems that incorporated the requirements and made it possible for records, as defined by the requirements, to be maintained in such systems.

\subsection{The UBC-MAS project}

The origins of the UBC-MAS project mirror those of the University of Pittsburgh project. According to Marsden (1997: 159), "the inescapable and well documented requirement for theoretical and practicable models to confront the intersection of technology and the management of records and information" led to the birth of the project. Specifically, the project set out to define the methods for ensuring reliability and authenticity of digital records based on diplomatics and archival concepts and principles. Duranti and MacNeil (1997) pointed out that the UBC-MAS project studied the authenticity and reliability of digital records from the point of view of the records creator, specifically a corporate body, because corporate bodies depend on creating and maintaining records that have integrity. The specific objectives of the project were to:

- establish what a record is in principle and how it can be recognised in the digital environment;

- determine what kind of digital systems generate records;

- formulate criteria that allow for the appropriate segregation of records from all other types of information in digital systems generating and/or storing a variety of data aggregations; 
- define the conceptual requirements for guaranteeing the reliability and authenticity of records in digital systems;

- $\quad$ articulate the administrative, procedural and technical methods for the implementation of those requirements; and

- $\quad$ assess those methods against different administrative, juridical, cultural and disciplinary points of view (Duranti \& Eastwood 1995, Duranti \& MacNeil 1997).

Firstly, the UBC-MAS project defined the terms 'reliability' and 'authenticity', which, when combined, amount to integrity (Duranti 1995). Rogers (2015a) proposed that preserving the integrity of records means ensuring that they are created reliably and maintained authentically. The meaning of the concepts of reliability and authenticity were derived from diplomatics (Rogers 2015a). Reliability refers to the authority and trustworthiness of records as proof and memory of the activity, including their ability to represent the facts. Authenticity is defined as the trustworthiness of a record as a record: that it is what it purports to be and is free from tampering or corruption (Duranti 2001). The UBC-MAS project research team collaborated with the United States of America's Department of Defence Records Management Task Force and operationalised the research findings in the form of mandatory functional requirements for records management application software (Duranti, MacNeil \& Underwood 1996; MacNeil 2000). Through the collaborative research agenda, the two partners sought to interpret archival and diplomatic concepts using a standard modelling technique (Integrated Definition Language) (Duranti, Eastwood \& MacNeil 2002). According to Duranti and MacNeil (1997:64), the results of the tests of validity of traditional archival and diplomatic concepts were found to provide a "powerful and internally consistent methodology for preserving the integrity of digital records."

\subsection{International Research on Permanent Authentic Records in Electronic Systems (InterPARES)}

Another project that studied the management of records in the digital environment is commonly known as InterPARES (Duranti 2009). Based at the University of British Columbia in Canada, InterPARES is the longest running and longest continuously funded research project into the preservation of authentic digital records (Rogers 2015a). In the words of Duranti (2009: 3006), "InterPARES has developed knowledge essential to the long-term preservation of authentic records created and/or maintained in digital form, and provided the basis for standards, policies, strategies and plans of action capable of ensuring the longevity of such material and the ability of its users to trust its authenticity."

InterPARES I (1999-2001) focused on the preservation of the authenticity of digital records no longer required for operational and business purposes (InterPARES 2005). The records examined were primarily textual documents produced and maintained in databases and document management systems. According to Rogers (2015b), the definitions of 'reliability', 'authenticity', 'record' and 'digital record' adopted and developed by the previous UBC project formed the basis of inquiry. InterPARES 1 had its epistemological roots in the humanities, specifically in diplomatics and archival science (Duranti 2007). It sought to establish the means for assessing and maintaining the authenticity of digital records once they become inactive and are selected for permanent preservation (InterPARES 2005). Research teams were drawn from across the globe and came from disciplines such as law, history, computer science and engineering, information science, and chemistry. However, the project's key concepts and methodologies were drawn from diplomatics and archival science (InterPARES 2005). InterPARES 1 comprised taskforces, one of which was the Authenticity Task Force. The Authenticity Task Force developed benchmark requirements that supported the presumption of the authenticity of digital records before they are transferred to the preserver's custody and those that supported the production of authentic copies of digital records after they have been transferred to the preserver's custody (InterPARES 2005, Rogers 2015b).

InterPARES 2 (1999-2001) built upon the findings of InterPARES 1 and sought to address the challenge of the permanent preservation of reliable, accurate and authentic digital records created and maintained in interactive and dynamic systems in the course of a variety of human activities (Duranti 2007; InterPARES 2008). Being archival in nature, the ultimate goal of InterPARES 2 was the development of a trusted record-making and record-keeping system and of a preservation system capable of ensuring the authenticity of the records under examination over the long term (Duranti 2007). Thus, the work carried out throughout the project in the various disciplinary areas had to be constantly translated into archival terms and linked to archival concepts, which are the foundation upon which the systems intended to protect the records. In terms of research methodology, InterPARES adopted no epistemological perspective. According to InterPARES (2008), the second InterPARES project probed the issues of reliability and accuracy during the entire lifecycle of records, from creation to permanent preservation. Domains that drove the project focused, firstly, on digital records creation and maintenance and, secondly, on authenticity, reliability and accuracy of digital records in the artistic, scientific and governmental sectors and methods of appraisal and preservation.

Among its key products, InterPARES 2 produced a set of guidelines for creators and preservers that operationalised the benchmark and baseline requirements that emanated from InterPARES 1 and was a further development of it (Roeder et al. 2008). The guidelines were developed with input from archival scholars, practicing archivists and specialists in the arts, sciences and government. Roeder et al. (2008) acknowledged the usefulness of the guidelines in informing the 
preservation of digital records but pointed out that they should not be used blindly as they have not exhausted all preservation-related issues. Despite this cautionary measure, Rogers (2015a) noted that the guidelines are still highly referenced and used, as evidenced by the frequency of downloaded resources from the InterPARES website. The other products of InterPARES 2 were a framework of principles guiding the development of policies for organisations that create and preserve records; guidelines for making and maintaining digital records for individuals and small communities of practice; guidelines for digital preservation for archival institutions; a metadata registry for the registration and analysis of metadata schemas; a chain of preservation model; principles and criteria for the adoption of file formats, wrappers and encoding; and a terminology database (Duranti 2007, Roeder et al. 2008).

InterPARES 3 took place from 2007 to 2012. It built upon the findings of InterPARES 1 and 2 and other digital preservation projects worldwide (Rogers 2015a). It used findings from the previous InterPARES projects and other research projects to put theoretical concepts into practice by applying research findings of the previous two phases through case studies with small and medium-sized organisations, or those with limited resources. For example, Rogers et al. (2013) undertook a study to develop policy and procedures for the preservation of digital records at the British Columbia Institute of Technology (BCIT). The case study followed the general case study methodology determined by InterPARES. Data collected from standardised InterPARES questionnaires and interview protocols were measured against the InterPARES benchmark and baseline requirements for the creation and preservation of authentic reliable records to conduct a gap analysis in order to determine deficiencies in current practice. At the end, Rogers et al. (2013) indicated that a policy and records management procedures for digital records were developed using the InterPARES framework of principles for the development of policies. The policy and procedures included strategies and standards for the long-term preservation of digital records as a guide for content that reflected best practice as well as existing BCIT records management policy and procedures as a guide for form.

InterPARES 4 (2013-2018) was known as InterPARES Trust. It studied issues of trust in records maintained and used in online environments (Rogers 2015a). According to the InterPARES Trust website (InterPARES Trust 2018), the InterPARES Trust research project comprises multidisciplinary teams from across the globe. The focus of research is on exploring issues concerning digital records and data entrusted to the internet. The main goal is to produce theoretical and methodological frameworks applicable for developing local, national and international policies, procedures, regulations, standards and legislation that can assist in ensuring public trust grounded in evidence of good governance, a strong digital economy and a persistent digital memory.

\section{Conceptual framework}

This study used archival diplomatics as a theoretical lens in its endeavour to assess the authenticity of digital records (Eastwood 1994, Duranti, Eastwood \& MacNeil 2002, Duranti 2009) in the GABS of the Botswana government. Archival diplomatics is a concept derived from the words 'archival science' and 'diplomatics'. Archival diplomatics provides a specified view of a model record and the means of understanding and defining record authenticity, including elements that comprise it. Duranti, Eastwood and MacNeil (2002) pointed out that diplomatics deals with the concept of archival documents in the singular since its analysis is at item level. Accordingly, this approach suits the aims of identifying elementary components (medium, physical form, intellectual form, persons, action, context, archival bond, content) of individual records that are recognised by electronic systems and their functionality in terms of the ability to control entities within the system at item level. Notably, the objective of diplomatics is not to study any document, but to study only archival documents, that is, documents created or received by a physical or juridical person in the course of a practical activity (Duranti \& Thibodeau 2006, Duranti 2009). Duranti (2009) asserted that modern diplomatics concerns itself with defining and assessing the trustworthiness of records, that is their reliability and authenticity, which is the main purpose of this study.

Archival science shares similarities with diplomatics, but it considers records as aggregations and not as individual items (Duranti, Eastwood and MacNeil 2002). For archival science, a digital record must have: (1) an identifiable context; (2) identifiable persons concurring with its creation; (3) an action in which the record participates or which the record supports, either procedurally or as part of the decision-making process; (4) explicit linkages to other records within or outside the digital system through a classification code or other unique identifier; (5) a fixed form; and (6) stable content (Duranti \& Thibodeau 2006, Duranti \& Rogers 2012). According to Duranti and Rogers (2012), as evidence of business activities and transactions, records are to be understood in the context of their creation, which is basically the framework for action. Thus, records produced within the juridical/administrative, provenance, procedural, documentary and technological contexts are considered authentic, reliable and accurate, and therefore have integrity and are deemed trustworthy. This study applied archival diplomatics to investigate whether records created through GABS are authentic and remain reliable for as long as needed. 


\section{Aim and objectives of the study}

A research aim usually precedes a series of statements describing a project's research objectives (Thomas \& Hodges 2010: 38). The main aim of this study was to assess digital records authenticity in a Botswana government accounting system, using archival diplomatics as a theoretical lens. The specific objectives were:

- To establish whether records generated and stored in GABS possess the qualities of an authentic record which are identity and integrity

- To find out if records generated through GABS possessed the characteristics of digital records as theorised by archival diplomatics.

\section{Methodology}

The study used a qualitative approach and a case study research design. Data were collected from ICT professionals, who were sampled purposively, through documentary review and through system analysis. System analysis is the process of data collection and interpretation of facts, identifying problems and a decomposition of a system into its components. It is undertaken for purposes of studying a system or its constituent parts in order to identify its objectives (Tutorials Point 2015). According to Livari, Parsons and Wand (2006), the purpose of system analysis is to identify and document the requirements for an information system to support organisational activities. In the absence of a statement of user requirements for GABS, the researcher resorted to interviewing ICT specialists, some of whom performed the roles of system analyst to obtain information of capabilities of GABS for creating and storing authentic digital records. Documentary sources in the form of texts and documents provide useful data about society, both historically and the present (Walliman 2011). Yin (2009) observed that, in a case study, document analysis plays a noteworthy role. Studies by Ngoepe and Makhubela (2015) and Wamukoya and Mutula (2005b) used documentary analysis when investigating records management and the travesty of justice in South Africa and the capacity building requirements for digital records management practices in the Eastern and Southern Africa Regional Branch of the International Council on Archives (ESARBICA) region, respectively. Purposive sampling was used to select ICT experts who took part in the study.

\section{Findings of the study}

The findings of the study are presented in accordance with the study objectives. Firstly, the findings related to the identity and integrity of records generated in GABS are presented, followed by findings related to whether records generated in GABS possessed the characteristics of digital records as theorised by archival diplomatics.

\subsection{Identity and integrity of records generated and stored in GABS}

The first of the objectives of the study was to establish whether records generated and stored in GABS are identifiable and have integrity, which are the qualities of an authentic record. Central to the assessment of records authenticity in digital systems are identity and integrity metadata (InterPARES 2002, Duranti \& Blanchette 2004, Duranti 2014). Rogers (2015b) said that the principles of archival diplomatics are used to identify records in digital systems, including an assessment of their authenticity. Other than that, Duranti and Blanchette (2004) stated that, in archival theory (a component of archival diplomatics), records used to transact organisational business are regarded as authentic. These findings reveal that the identity of records (a component of records authenticity) created through GABS can be established because the system is able to capture and store the following core information or metadata about digital records that are persistently linked to it over time and across hardware and software platforms for purposes of establishing and perpetuating the record's identity and integrity. The metadata for the identity of the record included the following:

- Name of author (in the form of the office and or physical person responsible, often present in the attestation of the record and in the subscribed signatures, although it is not always necessary for the perfection of the record)

- $\quad$ Addressee

- Writer

- Manifestation of the record's archival bond

- Indication of the action or matter to which the created record relates

- Indications of any attachments or annotations

Archival diplomatics theorises that for records to be deemed authentic, their identity must be established. Records in GABS are identifiable because the components of a record - its author, addressee, writer or originator, its date, the name of the action or matter, its status of transmission (original, draft or copy), its relationship to the other records of the same creator, and the indication of attachments - are present (Guercio 2001, Duranti \& Blanchette 2004). In this regard, records 
in GABS are identifiable, but this does not mean they are authentic, because their integrity also needs to be determined if they are to be regarded as authentic.

The integrity of a record relates to its wholeness and soundness, that is, that it has not been tampered with and remains intact after creation or receipt (InterPARES 2002). The ICT professionals interviewed during the study indicated that the authenticity of records in GABS is maintained through information technology or system controls that are in place. These include the use of usernames and passwords, audit trails, built-in computer security mechanisms, segregation of duties, and a system that does not allow records to be deleted. A transaction can be cancelled, but such a record remains in the system. According to Rogers (2015b), computer system technical controls can be relied upon to maintain the authenticity of an electronic record. InterPARES (2002) stated that, in the electronic world, the fragility of the media, the obsolescence of technology and the idiosyncrasies of systems likewise affect the integrity of records which can be corrupted. However, if the elements that make up its identity remain, including the message communicated in the content, the record remains authentic even if the actual value of its constituent bit strings may be compromised. GABS was implemented in 2004 and its software platforms have been continually updated to ensure the records remain accessible, even in the face of obsolescence.

\subsection{Characteristics of digital records in GABS}

The second objective of the study sought to discover whether records generated and stored in GABS possessed the characteristics of digital records as theorised by archival diplomatics. According to Duranti (2010), digital records have the following characteristics: identifiable context, persons concurring to their creation, an act, archival bond, medium, fixed form and stable content. The findings from system analysis performed on GABS revealed that, as theorised by archival diplomatics, records in GABS have the following:

Fixed documentary form: Once a record is created in GABS, it cannot be deleted or modified. If such a record does not represent a transaction truthfully, it is turned into an image or shadow after a correct record replacing it is created; both exist in the system. These procedures are controlled. An action officer who discovers a record that does not provide truthful evidence of the transaction of which it forms a part can only report such a discovery. Another officer then turns the record into a shadow in the system. The roles and responsibilities tied to performing transactions in the system govern the incident. In essence, records in GABS are fixed and cannot be changed which aligns to the character of a record as viewed through an archival diplomatics lens.

Stable content refers to the message communicated or conveyed by the record. Various financial transactions are carried through the system and records serve as evidence of the very same transactions. 'Stable content' means that the entity's content must remain fixed and complete with no chance of being altered when in storage; the message it conveys remains unchanged and identical to when it was first produced (Duranti \& Jansen 2011).

Archival bond refers to the relationship that links each record to the previous one and the subsequent one (Duranti 2001). Transactions in GABS are related to others within and outside the system. For example, at the start of every financial year, budgeting is done and recorded in manual records. Once the budget is approved, it is captured onto the system. Thereafter, expenditure is recorded in the system following a process of requests and approvals which take place both in the system and outside of it (in the paper counterpart). The evidence (records) of transactions conducted through GABS are thus linked to each other, the subsequent record of the same action, and, incrementally, to all the records which participate in the same activity (InterPARES 2006).

Identifiable context: A digital record has a procedural, provenancial, juridical-administrative and technological context:

- The juridical-administrative context is the legal and organisational system in which the creating body belongs (InterPARES 2006). GABS operates within the confines of legislation applicable to financial management and control. Legislation includes the Public Finance Management Act, Public Audit Act and the Constitution of the Republic of Botswana (Mosweu \& Ngoepe 2018).

- Procedural context is made up of business procedure in the course of which a record is created (InterPARES 2006). According to InterPARES (2019: 41), a procedure refers to "a body of written and unwritten rules governing the conduct of a transaction, or the formal steps undertaken in carrying out a transaction." Business transactions conducted in GABS have procedures that are followed and have standardised operations, and these include those related to among others, loan applications, payments to suppliers and applications for daily allowances. For example, a procedure should be followed when an officer requests for an allowance to take a trip outside the country. It involves a trip requisition and approval for the payment of the monies into the travelling public officer's bank account.

- Provenancial context refers to the creating body, its mandate, structure and function (InterPARES 2007). In this case, the creating body of GABS is the AGD, which is the principal government entity entrusted with financial management and control of the central government of Botswana through the use of the system. 
- Technological context is defined as the characteristics of the technological components of a digital computing system in which records are created (InterPARES 2007). GABS is based on a standard ERP package, Oracle Financials. It was customised to meet the needs of the user department (AGD). Modules normally not found in a standard ERP, such as a Public Debt Unit function and the Revenue Office Data Capture Module, were added during customisation.

\section{Conclusion and recommendations}

The objectives of this study were twofold. The first was to determine whether GABS creates and maintains authentic records. Although by design it is not a recordkeeping system but a transactional one, it creates and maintains authentic accounting records because the records created and stored in the system are identifiable and have integrity - the two components that ensure the authenticity of a digital record. However, this authenticity is not guaranteed over time (Mosweu 2018). The second objective sought to determine whether digital accounting records in GABS possessed the characteristics of a record as theorised by archival diplomatics. It has been established by this study that records in the system have those characteristics and these include an identifiable context, persons concurring to their creation, an act, archival bond, medium, fixed form and stable content.

The study recommends that GABS, in order to enhance the authenticity of records in the system, be integrated with an Electronic Document and Records Management System (EDRMS) or even an Enterprise Content Management (ECM) system where one has been implemented by government and ministries of the Government of Botswana. GABS is versatile and can be integrated with other information systems. For instance, in a study that assessed the delivery of justice through the Court Records Management System at the Gaborone Magisterial District in Gaborone in Botswana, Mosweu (2012) discovered that, although the system's payment module for child maintenance could be integrated with GABS, it was not. Subsequently, child maintenance payments are being paid through GABS and receipts brought to the Magistrate Court as proof of payment.

\section{References}

Bearman, D. and Sochats, K. 2002. Functional requirements for evidence in recordkeeping: The Pittsburgh Project. [Online]. http://www.archimuse.com/papers/nhprc/BACartic.html (2June 2019).

Cox, R.J. 1997. Electronic systems and records management in the information age: an introduction. Bulletin of the American Society for Information Science and Technology, 23: 7-9. DOI:10.1002/bult.59.

Duff, W. 1996. Ensuring the preservation of reliable evidence: a research project funded by the NHPRC. Archivaria, 42: 28-45.

Duranti, L. 1995. Reliability and authenticity: The concepts and their implications. Archivaria, 39: 5-10.

Duranti, L. 1997. The archival bond. Archives and Museum Informatics, 11: 213-218.

Duranti, L. 2001. Concepts, principles, and methods for the management of electronic records. The Information Society, 17:271-279.

Duranti, L. 2007. Reflections on InterPARES - The InterPARES 2 Project (2002-2007): an overview. Archivaria, 64: 113121.

Duranti, L. 2009. From digital diplomatics to digital records forensics. Archivaria, 68: 39-66.

Duranti, L. 2010. The trustworthiness of digital records. Paper presented at the International Congress on Digital Records Preservation. 14-18 April. Beijing, China. [Online]. http://www.interpares.org/display_file.cfm?doc=ip3_canada_dissemination_cs_duranti_icdrp_2010.pdf (3 September 2019).

Duranti, L. 2014. Involuntary secondary permanence: do many copies replace the one original? [Online]. https://interparestrust.org/assets/public/dissemination/Duranti_2014_YaleLibraries.pdf (7 July 2020).

Duranti, L. and Blanchette, J.F. 2004. The authenticity of electronic records: The InterPARES approach. [Online]. https://pages.gseis.ucla.edu/faculty/blanchette/papers/ist2.pdf (2 May 2018).

Duranti, L. and Eastwood, E. 1995. Protecting electronic evidence: a progress report on a research study and its methodology. Archivi and Computer, 3: 213-250.

Duranti, L. and Jansen, A. 2011. Authenticity of digital records: an archival diplomatics framework for digital forensics. Paper presented at the 5th European Conference on Information Management and Evaluation. 8-9 September. Como, Italy. [Online]. https://www.researchgate.net/publication/290042000_Authenticity_of_digital_records_An_archival_diplomatics_fram ework_for_digital_forensics (21 April 2018).

Duranti, L. and MacNeil, H. 1996. The protection of the integrity of electronic records: an overview of the UBC-MAS Research Project. Archivaria, 42: 46-67.

Duranti, L. and MacNeil, H. 1997. The preservation of the integrity of electronic records: an overview of the UBC-MAS research project. Archivaria, 42: 46-67.

Duranti, L. and Rogers, C. 2012. Trust in digital records: an increasingly cloudy legal area. Computer Law \& Security Review, 28(5): 522-531. 
Duranti, L. and Thibodeau, K. 2006. The concept of record in interactive, experiential and dynamic environments: the view of InterPARES. Archival Science, 6(1): 13-68.

Duranti, L., Eastwood, T. and MacNeil, H. 2002. Preservation of the integrity of electronic records. Dordrecht: Springer.

Duranti, L., MacNeil, H. and Underwood, W.E. 1996. Protecting electronic evidence: a second progress report on a research study and its methodology. Archivi \& Computer, 6(1): 37-70

Eastwood, T. 1994. What is archival theory and why is it important? Archivaria, 37: 122-130.

Evans, D. and Yen. D.C. 2005. E-government: an analysis for implementation: framework for understanding cultural and social impact. Government Information Quarterly, 29-41.

Fang, Z. 2002. E-government in digital era: concept, practice, and development. International Journal of the Computer, the Internet and Management, 10(2): 1-22.

Guercio, M. 2001. Principles, methods, and instruments for the creation, preservation, and use of archival records in the digital environment. American Archivist, 64(Fall/Winter): 238-269.

InterPARES. 2002. Requirements for assessing and maintaining the authenticity of electronic records. [Online]. http://www.interpares.org/book/interpares_book_k_app02.pdf (10 September 2019).

InterPARES. 2005. The long-term preservation of authentic electronic records: findings of the InterPARES Project. [Online]. http://www.imaginar.org/taller/dppd/DPPD/126\%20pp\%20InterPARES.pdf (7 July 2020).

InterPARES. 2006. Diplomatic Analysis: Case Study 03: HorizonZero/ZeroHorizon Online Magazine and Database. [Online]. http://www.interpares.org/display_file.cfm?doc=ip2_cs03_diplomatic_analysis.pdf (8 September 2019).

InterPARES. 2007. Diplomatic Analysis: case study. [Online]. http://interpares.org/ip3/display_file.cfm?doc=ip3_template_for_diplomatic_analysis.pdf (7 September 2019).

InterPARES. 2008. International Research on Permanent Authentic Records in Electronic Systems (InterPARES) 2: Experiential, Interactive and Dynamic Records: Glossary. [Online]. http://www.interpares.org/ip2/display_file.cfm?doc=ip2_book_glossary.pdf (20 January 2019).

InterPARES. 2019. The InterPARES 2 Project: Glossary. [Online]. http://www.interpares.org/ip2/display_file.cfm?doc=ip2_glossary.pdf\&CFID=19186715\&CFTOKEN=18204066 (7 September 2019).

InterPARES Trust. 2018. InterPARES Trust. [Online]. https://interparestrust.org/.

Jansen, A. 2014. Authenticity in records systems: emerging research in digital preservation. Proceedings of the APA/CDAC International Conference on Digital Preservation and Development of Trusted Digital Repositories. 5-6 February. New Delhi, India: C-DAC \& APA. 39-46.

Livari, J, Parsons, J. and Wand, Y. 2006. Research in information systems analysis and design: introduction to the special issue. Journal of the Association for Information Systems, 7(8): 509-513. [Online]. https://pdfs.semanticscholar.org/112b/1cfef3687c56d9855481f2d21dd5b59ba590.pdf (10 September 2019).

MacNeil, H. 2000. Trusting records: legal, historical, and diplomatic perspectives. Dordrecht: Kluwer Academic.

Mak, B. 2012. On the uses of authenticity. Archivaria, 73: 1-17.

Makhura, M.M. 2005. The contribution of records management towards an organisation's competitive performance. $\mathrm{PhD}$ thesis. University of Johannesburg.

Marsden, P. 1997. When is the future? Comparative notes on the electronic record-keeping projects of the University of Pittsburgh and University of British Columbia. Archivaria, 43: 158-173.

Mosweu, O. 2018. A framework to authenticate records in a government accounting system in Botswana to support the audit process. PhD thesis. University of South Africa.

Mosweu, O. and Ngoepe, M. 2018. Legal framework for auditing public sector accounting records in the digital environment in Botswana. In Proceedings of the 9th ProLISSA Conference. M. Fombad \& M. Ngoepe, Eds. Newcastle upon Tyne: Cambridge Scholars.

Mosweu, T. 2012. An assessment of the Court Records Management System in the delivery of justice in the Gaborone Magisterial District. Master's thesis. University of Botswana.

Ngoepe, M. and Makhubela, S. 2015. Justice delayed is justice denied: records management and the travesty of justice in South Africa. Records Management Journal, 25(3): 288-305.

Park, E.G. 2001. Understanding "authenticity" in records and information management: analysing practitioner constructs. American Archivist, 64: 270-291.

Roeder, J., Eppard, P., Underwood, W. and Lauriault, T. 2008. Authenticity, reliability and accuracy of digital records in the artistic, scientific and governmental sectors. [Online].

http://www.interpares.org/ip2/display_file.cfm?doc=ip2_book_part_3_domain2_task_force.pdf (16 November 2018).

Rogers, C. 2015a. Record authenticity as a measure of trust: a view across records professions, sectors, and legal systems. INFuture2015: e-Institutions - Openness, Accessibility, and Preservation, 13: 109-118.

Rogers, C. 2015b. Virtual authenticity: authenticity of digital records from theory to practice. PhD thesis. University of British Columbia.

Rogers, R., Daum, P., Shaffer, E. and Allen, A. 2013. Case Study 01 - British Columbia Institute of Technology (BCIT): policies and procedures for preservation of digital records: case study report. [Online]. http://interpares.org/ip3/display_file.cfm?doc=ip3_canada_cs01_final_report.pdf (16 November 2019).

Sisman, A. 2012. The e-government concept and e-government applications. In Handbook of Research on E-Government in Emerging Economies: Adoption, E-Participation, and Legal Frameworks. K.J. Bwalya \& S. Zulu, Eds. Hershey, PA: IGI Global. 411-422. 
South Carolina. 2007. Trustworthy information systems handbook. [Online]. https://scdahtest.sc.gov/sites/default/files/Documents/Records\%20Management\%20(RM)/Electronic\%20Records/Trustworthy\%20 Information\%20Handbook/TIShndbk1and2.pdf (24 November 2018).

Stair, R.M. and Reynolds, G.W. 2006. Principles of information systems: a managerial approach. Boston: Thomason Learning.

Tafor, V. 2003. Digital technology - understanding the problems posed by information technology in generating and managing records from a third perspective. ESARBICA Journal, 22: 72-77.

Thomas, D.R. and Hodges, I. 2010. Designing and planning your research project: core skills for social and health researchers. Los Angeles: Sage

Tutorials Point. 2015. Systems analysis and design. [Online]. https://www.tutorialspoint.com/system_analysis_and_design/system_analysis_and_design_tutorial.pdf (20 May 2018).

Walliman, N. 2011. Research methods: the basics. New York: Routledge.

Wamukoya, J. and Mutula, S.M. 2005a. E-records management and governance in East and Southern Africa. Malaysian Journal of Library \& Information Science, 10(2): 67-83.

Wamukoya, J. and Mutula, S.M. 2005b. Capacity-building requirements for e-records management: the case in East and Southern Africa. Records Management Journal, 15(2): 71-79.

Yin, R.K. 2009. Case study research: design and methods. 4th edition. New Delhi: Sage. 